\title{
Readability and content analysis of lifestyle education resources for weight management in Australian general practice \\ (1) CrossMark
}

\author{
Nouhad El-Haddad ${ }^{1,2^{*}}$, Catherine Spooner ${ }^{1,2}$, Nighat Faruqi ${ }^{1,2}$, Elizabeth Denney-Wilson ${ }^{2,3}$ and Mark Harris ${ }^{1,2}$
}

\begin{abstract}
Background: Weight management education is one of the key strategies to assist patients to manage their weight. Educational resources provide an important adjunct in the chain of communication between practitioners and patients. However, one in five Australian adults has low health literacy. The purpose of this study was to assess the readability and analyse the content of weight management resources.

Methods: This study is based on the analysis of 23 resources found in the waiting rooms of ten Sydney-based general practices and downloaded from two clinical software packages used at these practices. The reading grade level of these resources was calculated using the Flesch Reading Ease, Flesch-Kincaid Grade Level, Fry Readability Graph, and the Simplified Measure of Gobbledygook. Resources' content was analysed for the presence of dietary, physical activity, and behaviour change elements, as recommended by the Clinical practice guidelines for the management of overweight and obesity in adults, adolescents, and children in Australia.

Results: The resources' average reading grade level was for a $10^{\text {th }}$ grader $(9.5 \pm 1.8)$. These findings highlight that the average reading grade level was two grades higher than the recommended reading grade level for health education resources of 8th grade level or below. Seventy percent of resources contained dietary and behaviour change elements. Physical activity was included in half of the resources. Two messages were identified to be inconsistent with the guidelines and three messages had no scientific basis.

Conclusion: A body of evidence now exists that supports the need to develop evidence-based education resources for weight management that place low demand on literacy, without compromising content accuracy. The findings from this study suggest that there is significant room for improvement in the educational resources provided in general practices.
\end{abstract}

Keywords: Educational resources, Weight management, Lifestyle, Nutrition, Physical activity, Health literacy, Readability, Content analysis, General practice

\section{Background}

Obesity is a major global health concern. In Australia, obesity is common among general practice patients [1]. Approximately $70 \%$ of Australian men and $56 \%$ of Australian women were classified as overweight or obese in 2012 [2].

\footnotetext{
* Correspondence: nouhad.el-haddad@student.unsw.edu.au

${ }^{1}$ Centre for Primary Health Care and Equity, UNSW Australia, New South

Wales, Australia

${ }^{2}$ Centre for Obesity Management and Prevention Excellence in Primary

Health Care, UNSW Australia, New South Wales, Australia

Full list of author information is available at the end of the article
}

The Australian National Health and Medical Research Council (NHMRC) Clinical practice guidelines for the management of overweight and obesity in adults, adolescents, and children in Australia (the NHMRC Guidelines) provide recommendations for obesity management in general practice [3]. According to these guidelines, patient education should encourage healthy nutrition that create a required energy deficit, increased physical activity and strategies for behaviour change [4]. These lifestyle interventions are generally the first approach used by general practitioners (GPs) in assisting patients to manage their weight $[3,5]$. GPs are encouraged to 
educate their patients on weight loss and lifestyle change [6-13]. This can provide support for patient's behavioural change when combined with other interventions $[6-8,10-14]$.

Patient educational resources for weight management can provide a cost-effective way to reinforce verbal information provided by health professionals and promote behaviour change in overweight patients [3]. However, in Australia, one in five adults do not have adequate health literacy skills to understand health information $[2,15]$ and use it to make suitable changes to their weight [15]. Patients with better knowledge of their condition and its management have better outcomes [4]. Educational resources could increase patient's knowledge and understanding of weight management if they met the reading ability of the general population [15]. One of the elements for comprehending text is readability, which refers to the understandability of written text [16]. Readability can be calculated using a formula that determines the reading ability needed to understand a piece of text [16]. South Australia (SA) Health recommend that the level of readability of health information should be at a reading level of an eighth grader [17], which is the level of a 13 to 16 year old with 8 years of Australian education [18].

To our knowledge, no previous research has assessed the readability and analysed the content of lifestyle educational resources for weight management available for patients of the Australian primary health care system. A Canadian study assessed the readability of physical activity educational resources and found that the readability of the resources were above the average reading ability of adults (grade 10 or above) [15]. Studies on other health topics reported similar results. These include studies on paediatric care $[19,20]$, mental health [21], medication side effects and complications [22], hay fever [23], sleep disorders [24], stroke rehabilitation [25, 26], anticoagulant therapy [27], cholesterol [28], oral health and skin care for pressure ulcers [29].

The primary aim of this study was to assess the reading grade level of lifestyle educational resources for weight management available in Australian general practices. The secondary aim of this study was to analyse the content of the education resources in relation to the NHMRC Guidelines.

\section{Methods}

Lifestyle educational resources for weight management that included nutrition and/or physical activity information, were collected from ten general practices in South Western Sydney recruited as part of a cluster randomised control trial [30]. The practices served a diverse population that included people from non-English speaking and socioeconomically disadvantaged backgrounds, with obesity and low health literacy. The aim of trial was to evaluate a multi-level intervention for obese patients with low health literacy attending primary health care. The trial's protocol has been previously published [30]. Educational resources, which satisfied the eligibility criteria were collected from the practices' waiting rooms. Additionally appropriate resources were identified from the two clinical management software used in these practices. In Australia, these software's are commonly used by general practices to manage patients' clinical information, drug prescription and are a source for patient educational resources.

Educational resources included in this study were published in English, targeted patients aged 18 years or older and aimed at providing lifestyle education for weight management, including nutrition and/or physical activity information. Educational resources were excluded if they provided nutrition and/or physical information not specifically related to weight management, including pregnancy, breastfeeding, children, adolescents, allergies, intolerances, cancer, gastrointestinal disorders and any chronic condition including cardiovascular disease and diabetes.

The first author (NEH) assessed every educational resource recorded in the software packages and located in the waiting rooms for eligibility. The list of resources and their classification according to the inclusion criteria were verified with the co-authors (CS, NF and $\mathrm{MH}$ ) and discrepancies were discussed between the researchers.

\section{Readability analysis}

The readability of included resources was determined by the use of Flesch Reading Ease score [31], FleschKincaid Grade Level (FKGL) [32], Fry Readability Graph [33] and the Simplified Measure of Gobbledygook (SMOG) Grade [34]. The Flesch Reading Ease score and the FKGL were used because of their widespread use and validation for calculating readability [16, 31, 32]. Fry Readability Graph and SMOG were selected because both are commonly used and are suitable to assess the readability of patient educational material and health information [35]. These readability tools have been previously validated [16]. The Flesch Reading Ease score is based on the average number of words in the sentence and the average number of syllables per 100 words [31]. The Flesch Reading Ease formula produces a reading score between 0 and 100. A higher score means that the text is considered easier to understand; whereas a lower score indicates a more difficult text to read [31]. A reading ease score between 60 and 70 is considered acceptable [31]. The Flesch Reading Ease score was converted to a reading grade level (Table 1) and compared with reading grade levels calculated with the other readability tools [32]. The FKGL is based on the average number of 
Table 1 Interpretation of the reading ease formula [31]

\begin{tabular}{lll}
\hline Reading grade level & Verbal description & Reading ease \\
\hline 5 & Very easy & $90-100$ \\
6 & Easy & $80-89$ \\
7 & Fairly easy & $70-79$ \\
$8-9$ & Standard & $60-69$ \\
$10-12$ & Fairly difficult & $50-59$ \\
$13-16$ & Difficult & $30-49$ \\
Above 16 & Very difficult & $0-29$ \\
\hline
\end{tabular}

words per sentence and the average number of syllables per word [32]. SMOG Grade is based on the square root of the number of words with three or more syllables per 30 sentences [34]. SMOG Grade is considered the gold standard for evaluating health information [16]. The scores from FKGL and SMOG Grade corresponds to the number of formal school years necessary to understand the text [32]. Fry Readability Graph is based on the average number of sentences per 100 words and the number of syllables per 100 words [33]. Average scores were plotted onto the Fry Graph (Fig. 1). The intersection of the average number of sentences and the average number of syllables lines indicates the average reading grade level of the text.

Flesch Reading Ease and FKGL predict the reading grade level based on $75 \%$ comprehension, Fry Readability Graph predicts the reading grade level based on $90 \%$ comprehension, while SMOG Grade predicts the reading grade level based on $100 \%$ comprehension and complete understanding of health information. The reading grade levels yielded from the four readability tools were compared. The reading grade levels are based on US grade levels, which are equivalent to Australian grade levels [18].

The title and content of eligible resources were pasted into an automated online program as plain text (i.e. without pictures, bullets, abbreviations, and text boxes) that calculated performed the various formulas [36]. To check for accuracy, the word and sentence count obtained by the online program were manually confirmed.

Readability test data were entered and analysed descriptively for mean and standard deviation (SD) values using the SPSS Statistical Package, version 22.0 (SPSS INC., Chicago, IL, USA).

\section{Content analysis}

Each identified educational resource was assessed for the presence or absence of three overarching content elements: diet; physical activity; and behaviour change.

The three dietary content elements were: advice to eat more of the healthy food groups; limit intake of highenergy foods and drinks; and reduce total energy intake. These elements were chosen because the NHMRC Guidelines and the Australian Dietary Guidelines [3, 37] recommend that dietary advice should focus on creating

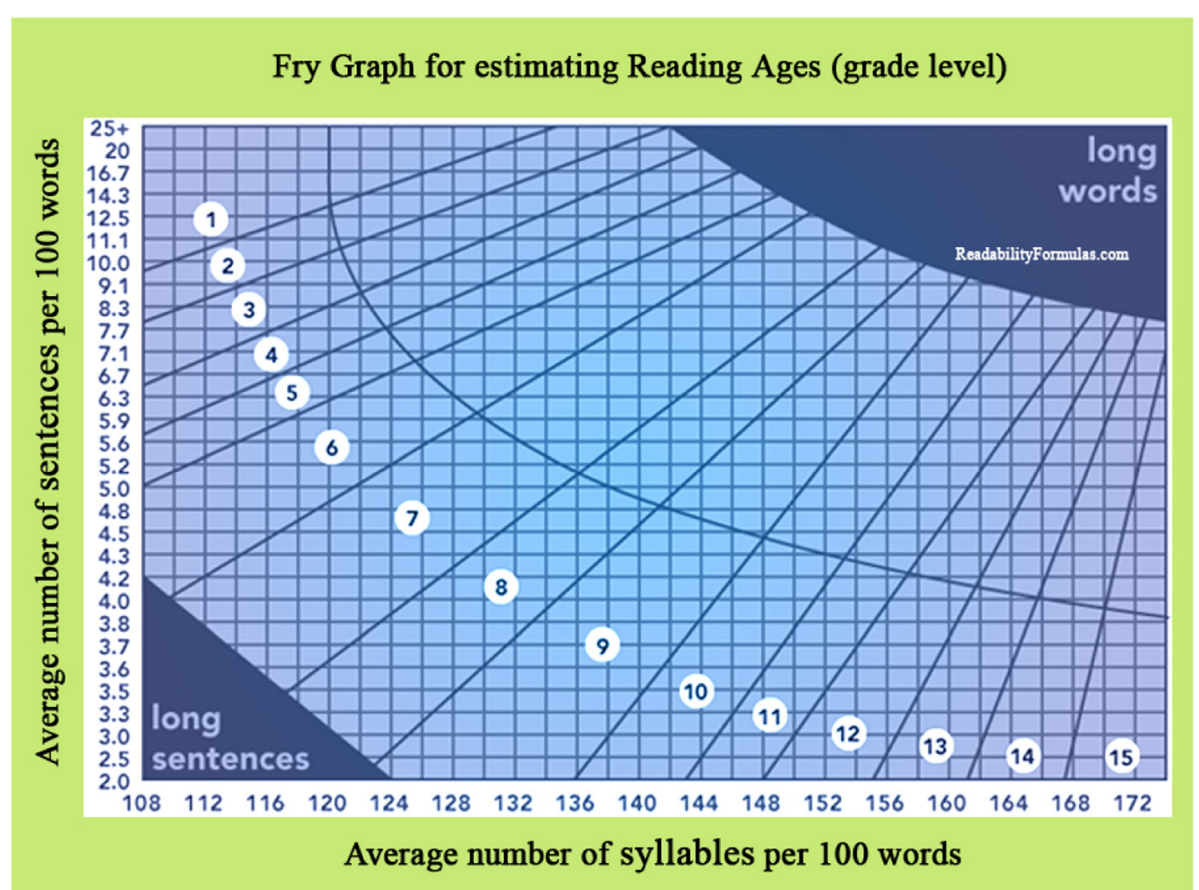

Fig. 1 Fry Readability Graph for estimating the reading grade level [33] 
an energy deficit and include a wide variety of nutritious foods.

The three physical activity elements were: advice to participate in approximately $300 \mathrm{~min}$ of moderateintensity activity; $150 \mathrm{~min}$ of vigorous activity; or an equivalent combination of moderate-intensity and vigorous activity each week combined, in conjunction with reduced dietary intake. These elements were chosen because the NHMRC Guidelines recommend these levels of physical activity for adults with overweight or obesity [3].

The five behavioural change content elements were: goal setting; self-monitoring of behaviour and progress; stimulus control; cognitive restructuring; and problem solving. These elements were chosen because the NHMRC Guidelines include the following examples of core strategies to support behavioural change for weight management [3].

Messages that were ambiguous, confusing or conflicted with the NHMRC Guidelines were noted for further investigation.

\section{Results}

Twenty-three educational resources were included in this study (Table 2). The majority of the educational resources were from commercial sources $(n=15)$, seven were from not-for-profit organisations and one was from a government source. Of the 23 resources, most $(n=17)$ were published between 2004 and 2014. Six resources did not include the date of publication. One of the resources was discontinued from publishing since 2010. Of the 23 resources, six were directly related to body weight and weight management, eight were focused on nutrition, six on physical activity, and three included information on a general healthy lifestyle.

\section{Readability analysis}

Table 2 shows the reading grade level of the resources. Four resources, entitled "Achieving and maintaining a healthy weight", "Eat for health", "Heart disease reduce the risk" and "Stay in shape", achieved the lowest reading grade level. Their average reading grade was noted at $8^{\text {th }}$ grade. Four resources, entitled "Healthy eating", "Physical activity", "Physical activity and exercise: getting started" and "Why be active", achieved the highest average reading grade level of a $12^{\text {th }}$ grader. Two of these resources, "Healthy eating" and "Physical activity", contained the most comprehensive information out of the 23 resources. One educational resource, "Achieving and maintaining a healthy weight", placed one of the lowest literacy demands on readers $(7.6 \pm 1.4)$ and covered all of the weight management messages. Resources produced by not-for-profit organisations had a readability range from $8^{\text {th }}$ to $12^{\text {th }}$ grade $(9.7 \pm 1.4)$; the one resource produced by the government had a readability score of $10^{\text {th }}$ grade $(9.9 \pm 1.7)$; and those produced commercially had a readability range from $8^{\text {th }}$ to $12^{\text {th }}$ grade $(9.6 \pm 2.0)$.

The average reading grade level calculated by SMOG Grade (12 \pm 1.4$)$ was higher compared with Flesch Reading Ease (8.6 \pm 1.4$)$, FKGL $(8.7 \pm 1.4)$ and Fry Readability $(9.4 \pm 1.4)$.

\section{Content analysis}

Table 3 shows the coverage of weight management messages for each resource. There was a broad range of messages covered. The most prevalent messages found in these resources were related to the consumption of more of the healthy food groups, reduction of total energy intake and support for behavioural change, more specifically goal setting and cognitive restructuring.

Dietary content elements - namely advice to eat more vegetables, fruit, wholegrain or high fibre cereals, lean meat or meat alternatives and reduce total energy intake- were covered in 16 out of the 23 resources. Advice to limit intake of high-energy foods and drinks were covered in 14 resources.

Physical activity content elements - namely advice to participate in approximately $300 \mathrm{~min}$ of moderateintensity activity and an equivalent combination of moderate-intensity and vigorous activity each week in conjunction with reduced dietary intake- was covered in 12 of the 23 resources. Advice to participate in $150 \mathrm{~min}$ of vigorous activity was covered in eight resources.

Behavioural change content elements - namely goal setting and cognitive restructuring- were covered in most resources (96 and $87 \%$ respectively). Stimulus control and problem solving were covered in 16 resources. A quarter (26\%) of the resources contained information on self-monitoring of behaviour and progress.

Two resources, "Achieving and maintaining a healthy weight" and "Obesity Q and A", provided the most comprehensive information, covering all 17 weight management messages. One resource, "Very low calorie diets: What you need to know", provided the least amount of information, covering only three messages.

Two messages that were inconsistent with the NHMRC Guidelines were identified. These were included in two resources, "Body weight and cancer risk" and "Medically supervised weight-loss program". They asserted that diets were ineffective and/or counterproductive. Additionally, one resource, "Medically supervised weight-loss program", contained multiple pieces of information that had no scientific basis. For example, it recommended using spicy foods and caffeine to reduce hunger and recommended slow weight loss as this approach prevented the negative 'bounce back' 
Table 2 Reading grade level estimates and descriptive data of included resources

\begin{tabular}{|c|c|c|c|c|c|c|c|c|c|}
\hline No. & Title & $\begin{array}{l}\text { Flesch reading } \\
\text { ease }\end{array}$ & $\mathrm{FKGL}^{\mathrm{a}}$ & $\begin{array}{l}\text { Fry } \\
\text { Readability }\end{array}$ & $\begin{array}{l}\text { SMOG }^{6} \\
\text { Grade }\end{array}$ & Average & Standard deviation & $\begin{array}{l}\text { Type of } \\
\text { publisher }\end{array}$ & $\begin{array}{l}\text { Year } \\
\text { published }\end{array}$ \\
\hline 1 & Body weight and cancer risk & 7.0 & 8.6 & 9.0 & 10.6 & 8.8 & 1.5 & Not-for-profit & 2014 \\
\hline 2 & Physical Activity & 10.0 & 11.2 & 14.0 & 12.9 & 12.0 & 1.8 & Not-for-profit & 2014 \\
\hline 3 & $\begin{array}{l}\text { Want to get more life out of life? } \\
\text { You can do something positive }\end{array}$ & 8.0 & 9.3 & 12.0 & 10.1 & 9.9 & 1.7 & Government & 2010 \\
\hline 4 & Eat for health & 7.0 & 6.6 & 7.0 & 9.6 & 7.6 & 1.4 & Not-for-profit & $N A^{c}$ \\
\hline 5 & Move your body & 8.5 & 7.8 & 9.0 & 10.9 & 9.1 & 1.3 & Not-for-profit & NA \\
\hline 6 & Stay in shape & 7.0 & 7.0 & 7.0 & 10.1 & 7.8 & 1.6 & Not-for-profit & NA \\
\hline 7 & Why be active? & 11.0 & 11.0 & 11.0 & 13.3 & 11.6 & 1.2 & Not-for-profit & NA \\
\hline 8 & $\begin{array}{l}\text { Very low calorie diets: What you } \\
\text { need to knowe }\end{array}$ & 8.0 & 9.2 & 15.0 & 12.4 & 11.2 & 3.2 & Commercial & NA \\
\hline 9 & Lifestyle choices for better health & 11.0 & 10.5 & 10.0 & 13.2 & 11.2 & 1.4 & Not-for-profit & 2012 \\
\hline 10 & $\begin{array}{l}\text { Medically supervised weight-loss } \\
\text { program }^{f}\end{array}$ & 7.71 & 7.0 & 9.1 & 9.9 & 8.4 & 1.3 & Commercial & NA \\
\hline 11 & Healthy eating & 12.0 & 12.8 & 9.0 & 14.4 & 12.1 & 2.3 & Commercial & 2005 \\
\hline 12 & Healthy takeaways & 7.0 & 7.8 & 8.0 & 11.1 & 8.5 & 1.8 & Commercial & 2005 \\
\hline 13 & High protein diets & 9.0 & 8.7 & 11.0 & 11.2 & 10.0 & 1.3 & Commercial & 2004 \\
\hline 14 & Reading food labels & 8.5 & 9.7 & 4.0 & 13.2 & 8.9 & 3.8 & Commercial & 2005 \\
\hline 15 & The facts on fat & 8.0 & 9.3 & 9.0 & 12.6 & 9.7 & 2.0 & Commercial & 2005 \\
\hline 16 & Weight control & 7.0 & 8.2 & 7.0 & 11.7 & 8.5 & 2.2 & Commercial & 2005 \\
\hline 17 & Achieving an adequate diet & 8.0 & 9.1 & 12.0 & 11.5 & 10.2 & 1.9 & Commercial & 2009 \\
\hline 18 & $\begin{array}{l}\text { Achieving and maintaining a } \\
\text { healthy weight }\end{array}$ & 7.0 & 6.7 & 7.0 & 9.6 & 7.6 & 1.4 & Commercial & 2008 \\
\hline 19 & Dietary guidelines for healthy eating & 8.0 & 8.5 & 10.0 & 11.4 & 9.5 & 1.5 & Commercial & 2009 \\
\hline 20 & Exercise: easing into it & 8.0 & 8.6 & 9.0 & 11.6 & 9.3 & 1.6 & Commercial & 2006 \\
\hline 21 & Heart disease reduce the risk & 7.0 & 5.9 & 8.0 & 9.0 & 7.5 & 1.3 & Commercial & 2009 \\
\hline 22 & Obesity $\mathrm{Q}$ and $\mathrm{A}$ & 9.0 & 7.2 & 8.0 & 10.1 & 8.6 & 1.3 & Commercial & 2010 \\
\hline 23 & $\begin{array}{l}\text { Physical activity and exercise: } \\
\text { getting started }\end{array}$ & 12.0 & 9.6 & 14.0 & 12.0 & 11.9 & 1.8 & Commercial & 2009 \\
\hline
\end{tabular}

${ }^{\mathrm{a}} F K G L$ flesch-kincaid grade level

${ }^{\mathrm{b}} \mathrm{SMOG}$ simplified measure of gobbledygook

${ }^{\mathrm{N}} \mathrm{NA}$ not available

${ }^{\mathrm{d}}$ This resource was available in English and in Arabic. It has been discontinued from publication

eThis resource is an advertisement for a meal replacement product as part of a very low calorie diet

'This is a series of educational resources as part of Professor Trim's medically supervised weight-loss program

phenomenon said to be associated with sudden weight loss.

\section{Discussion}

Weight management education is one of the key strategies to assist patients to manage their weight [6-13]. Educational resources provide an important adjunct in the chain of communication between practitioners and patients. This study found that the average reading grade level was two grades higher than the recommended reading grade level for health education resources of $8^{\text {th }}$ grade level or below [17]. The average reading grade level calculated by SMOG Grade was four grades higher than the recommended reading grade level. The average reading grade level calculated by Flesch Reading Ease and FKGL was one grade higher and the average reading grade level from Fry Readability Graph was two grades higher than the recommended reading grade level.

Our findings suggest that these resources would place high demands (reading grade level of a $12^{\text {th }}$ grader) on patients to understand all the information. These resources are likely to be difficult to comprehend for patients with low health literacy skills. The content analysis indicated that there was consistent information between the majority of the resources and the NHMRC Guidelines recommendation. The most prevalent messages found in the resources related to the consumption of more foods from the healthy food groups, reduction of total energy intake and support for behaviour change, specifically goal setting and cognitive restructuring. Only 
Table 3 Content analysis of included resources

\begin{tabular}{|c|c|c|c|c|c|c|c|c|c|c|c|c|c|c|c|c|c|}
\hline \multirow{2}{*}{ No. } & \multicolumn{9}{|l|}{ Diet } & \multicolumn{3}{|c|}{ Physical activity } & \multicolumn{5}{|c|}{ Behaviour change } \\
\hline & \multicolumn{4}{|c|}{$\begin{array}{l}\text { Advice to eat more of the } \\
\text { healthy food groups }\end{array}$} & \multicolumn{4}{|c|}{$\begin{array}{l}\text { Advice to limit intake of high-energy } \\
\text { foods and drinks }\end{array}$} & \multirow{2}{*}{$\begin{array}{l}\text { Advice } \\
\text { to } \\
\text { reduce } \\
\text { total } \\
\text { energy } \\
\text { intake }\end{array}$} & \multirow{2}{*}{$\begin{array}{l}300 \text { min } \\
\text { of } \\
\text { moderate- } \\
\text { intensity } \\
\text { activity/ } \\
\text { week }\end{array}$} & \multirow{2}{*}{$\begin{array}{l}150 \text { min } \\
\text { of } \\
\text { vigorous } \\
\text { activity/ } \\
\text { week }\end{array}$} & \multirow{2}{*}{$\begin{array}{l}\text { Combination } \\
\text { of } \\
\text { moderate- } \\
\text { intensity } \\
\text { and vigorous } \\
\text { activity each week } \\
\text { in conjunction with } \\
\text { reduced dietary } \\
\text { intake }\end{array}$} & \multirow{2}{*}{$\begin{array}{l}\text { Goal } \\
\text { setting }\end{array}$} & \multirow{2}{*}{$\begin{array}{l}\text { Self- } \\
\text { monitoring } \\
\text { of behaviour } \\
\text { and progress }\end{array}$} & \multirow[t]{2}{*}{$\begin{array}{l}\text { Stimulus } \\
\text { control }\end{array}$} & \multirow[t]{2}{*}{$\begin{array}{l}\text { Cognitive } \\
\text { restructuring }\end{array}$} & \multirow[t]{2}{*}{$\begin{array}{l}\text { Problem } \\
\text { solving }\end{array}$} \\
\hline & $\begin{array}{l}\text { Vegetables } \\
\text { and fruit }\end{array}$ & $\begin{array}{l}\text { Wholegrain/ } \\
\text { high fibre } \\
\text { cereals }\end{array}$ & $\begin{array}{l}\text { Lean } \\
\text { meat/ } \\
\text { alternatives }\end{array}$ & $\begin{array}{l}\text { Reduced } \\
\text { fat dairy } \\
\text { products }\end{array}$ & $\begin{array}{l}\text { Foods } \\
\text { high in } \\
\text { saturated } \\
\text { fat }^{\text {b }}\end{array}$ & $\begin{array}{l}\text { Foods } \\
\text { and } \\
\text { drinks } \\
\text { with } \\
\text { added } \\
\text { salt }\end{array}$ & $\begin{array}{l}\text { Foods } \\
\text { and } \\
\text { drinks } \\
\text { with } \\
\text { added sugar }{ }^{\text {a }}\end{array}$ & Alcohol & & & & & & & & & \\
\hline 1 & Y & Y & Y & - & - & Y & Y & Y & Y & - & - & Y & Y & Y & Y & Y & Y \\
\hline 2 & Y & Y & Y & - & - & Y & Y & Y & Y & Y & Y & Y & Y & - & Y & Y & Y \\
\hline 3 & Y & - & - & - & - & - & - & Y & - & Y & - & Y & Y & - & - & Y & - \\
\hline 4 & Y & Y & Y & Y & Y & Y & Y & Y & Y & - & - & - & Y & - & - & - & - \\
\hline 5 & - & - & - & - & - & - & - & Y & - & Y & Y & Y & Y & - & Y & Y & Y \\
\hline 6 & Y & Y & Y & Y & Y & Y & Y & - & Y & - & - & Y & Y & Y & Y & Y & Y \\
\hline 7 & - & - & - & - & - & - & - & - & - & Y & - & - & $Y$ & - & $Y$ & $Y$ & $Y$ \\
\hline 8 & - & - & - & - & - & - & - & - & Y & - & - & - & $Y$ & Y & - & - & - \\
\hline 9 & $Y$ & $Y$ & $Y$ & $Y$ & Y & $Y$ & $Y$ & $Y$ & - & Y & - & $Y$ & $Y$ & Y & $Y$ & $Y$ & $Y$ \\
\hline 10 & $Y$ & $Y$ & $Y$ & $Y$ & $Y$ & $Y$ & $Y$ & - & $Y$ & $Y$ & $Y$ & - & $Y$ & - & $Y$ & $Y$ & Y \\
\hline 11 & $Y$ & $Y$ & Y & $Y$ & $Y$ & $Y$ & $Y$ & $Y$ & $Y$ & $Y$ & $Y$ & $Y$ & $Y$ & - & - & $Y$ & Y \\
\hline 12 & $Y$ & $Y$ & Y & - & $Y$ & - & - & $Y$ & $Y$ & - & - & - & $Y$ & - & $Y$ & $Y$ & - \\
\hline 13 & $Y$ & $Y$ & $Y$ & - & - & - & $Y$ & - & - & - & - & - & $Y$ & - & $Y$ & $Y$ & - \\
\hline 14 & - & $Y$ & - & $Y$ & $Y$ & $Y$ & $Y$ & - & $Y$ & - & - & - & $Y$ & - & - & $Y$ & Y \\
\hline 15 & - & - & Y & $Y$ & Y & - & - & - & $Y$ & - & - & - & $Y$ & - & - & $Y$ & - \\
\hline 16 & $Y$ & $Y$ & Y & $Y$ & $Y$ & $Y$ & $Y$ & - & $Y$ & $Y$ & $Y$ & $Y$ & $Y$ & - & $Y$ & $Y$ & Y \\
\hline 17 & $Y$ & $Y$ & Y & $Y$ & $Y$ & $Y$ & $Y$ & $Y$ & $Y$ & - & - & - & - & - & - & - & - \\
\hline 18 & $Y$ & $Y$ & $Y$ & $Y$ & $Y$ & $Y$ & $Y$ & $Y$ & $Y$ & - & - & $Y$ & $Y$ & Y & $Y$ & $Y$ & Y \\
\hline 19 & $Y$ & $Y$ & $Y$ & $Y$ & $Y$ & $Y$ & $Y$ & $Y$ & $Y$ & $Y$ & - & $Y$ & $Y$ & - & $Y$ & $Y$ & Y \\
\hline 20 & - & - & - & - & - & - & - & - & - & $Y$ & $Y$ & - & $Y$ & - & $Y$ & Y & Y \\
\hline 21 & $Y$ & $Y$ & $Y$ & $Y$ & $Y$ & $Y$ & $Y$ & $Y$ & $Y$ & - & - & $Y$ & $Y$ & - & $Y$ & $Y$ & Y \\
\hline 22 & $Y$ & $Y$ & Y & $Y$ & $Y$ & $Y$ & $Y$ & $Y$ & $Y$ & $Y$ & $Y$ & $Y$ & $Y$ & Y & $Y$ & $Y$ & Y \\
\hline 23 & - & - & - & - & - & - & - & - & - & $Y$ & $Y$ & - & $Y$ & - & $Y$ & $Y$ & $Y$ \\
\hline
\end{tabular}

Foods and drinks with high-added sugar include confectionary, sugar-sweetened soft drinks and cordials, sugar-sweetened and no added sugar fruit drinks, vitamin waters, energy and sports drinks palm oil 
half of the resources covered some physical activity content elements. The NHMRC Guidelines strongly recommend a multicomponent intervention that incorporates reduced energy intake, increased physical activity and measures to support behaviour change $[3,5]$. Resources designed for weight management should also include information on physical activity.

Some messages were found to be inconsistent with the NHMRC Guidelines recommendations. Despite evidence that diets are effective for weight management [3], two resources asserted that diets were ineffective or counterproductive. Dietary interventions should be incorporated into a weight loss intervention and are designed to create an overall caloric deficit, suited to the individuals' needs and preferences [4]. The degree of adherence to the diet is the principal determinant of weight loss [3]. Another resource recommended slow weight loss as opposed to rapid weight loss to prevent the 'bounce back' phenomenon. However, a recent randomised control trial found that the rate of weight loss did not affect the proportion of weight regained within 144 weeks [38]. Also, rapid weight loss has a motivating effect, as seen in patients on a very low energy diet, although it is difficult to maintain in the long-term [39].

A number of claims were unsupported by published literature. A resource aimed at providing tips for reducing hunger suggested that consuming spicy food and caffeine before a main meal could act as a hungerreducing appetiser for weight loss. Caffeine has been found to aid weight loss because of its thermogenic effect $[40,41]$. A meta-analysis assessed the impact of green tea catechins (GTCs) with or without caffeine on body weight and found that GTCs with caffeine significantly decreased body weight when compared with a caffeine-free control [42]. However, the clinical significance of weight loss was modest [42]. Resources that recommend the consumption of caffeine to reduce hunger and assist with weight loss run the risk of encouraging unsafe caffeine use. For a healthy adult, caffeine intake exceeding $400 \mathrm{mg}$ per day is associated with adverse effects, such as general toxicity, insomnia, cardiovascular effects, effects on bone status and calcium balance, negative fluid balance caused by diuresis, changes in adult behaviour, increased incidence of cancer and effects of male fertility [43]. In relation to the spicy food claim, capsaicins, the pungent or hot compound in chilli peppers [44], are theorised to aid in weight loss because of their potential ability to increase energy expenditure and fat oxidation and decrease appetite. However, short-duration clinical trials have not demonstrated that capsaicins in spicy food are effective for weight loss among overweight or obese individuals [44-47]. Any effect on resting metabolic rate was approximately $50 \mathrm{cal}$ per day and not statistically significantly different to those in the placebo group [44, 45]. The long-term efficacy of spicy food to aid in weight loss has, therefore, not yet been tested.

The present study has several limitations. It is not an exhaustive study of resources available for weight management for patients attending general practice. The study only included educational resources published in English and those collected from medical software packages and the waiting room of the selected practices. The study did not include resources that GPs might download from the Internet or other sources. Second, the appraisal of a small sample of local general practices makes it difficult to generalise our findings as the results may underrepresent Australian practices. There may be resources used in other Australian practices with different readability and content. The authors also recognised that new resources continue to be developed. Third, other aspects of general readability were not assessed. These included the use of textual characteristics, such as font size, colour, bold and italics text to emphasise information, bulleted text, as well as instructional pictures, simplified sentences, sentence length, active and passive verbs and white space $[48,49]$. Finally, the current study did not seek the opinion of the patients. This could have provided useful information on the acceptability, suitability, usefulness and understanding of the educational resources. Hence, further studies that analyse the readability and content of a larger sample of weight management education resources and that evaluate the impact of these resources are recommended.

\section{Conclusion}

A body of evidence now exists that supports the need to develop evidence-based education resources for weight management that place low demand on literacy, without compromising content accuracy. This study suggests that educational resources commonly available in Australian general practice fall short of this. This has implications for general practice accreditation, which requires general practices to provide up-to-date resources of high quality and reliability for patients [50].

\section{Abbreviations \\ FKGL: flesch-kincaid grade level; GPs: general practitioners; GTC: green tea catechins; NHMRC: National Health and Medical Research Council; SA: South Australia; SD: standard deviation; SMOG: simplified measure of gobbledygook; SPSS: statistical package for the social sciences.}

\section{Competing interests}

The authors declare that they have no competing interests.

\section{Authors' contributions}

NEH was involved in the study design, data collection, extraction and analysis, and preparation and revision of the manuscript. CS was involved in the study design, verified the analysis, commented on the manuscript draft and approved the final manuscript. NF was involved in the study design,

verified the analysis, commented on the manuscript draft and approved the 
final manuscript. EDW provided advice on study, edited and commented on the manuscript draft and approved the final manuscript. $\mathrm{MH}$ was involved in the planning and study design, verified data extraction and analysis, commented on the manuscript draft and approved the final manuscript. All authors read and approved the final manuscript.

\section{Acknowledgements}

The study reported in this paper is a project of the Centre for Obesity Management and Prevention Research Excellence in Primary Health Care (COMPaRE-PHC) funded by the Australian Primary Health Care Research Institute, which is supported by a grant from the Australian Government Department of Health under the Primary Health Care Research, Evaluation and Development Strategy. The information and opinions contained in this paper do not necessarily reflect the views or policies of the Australian Government Department of Health and Ageing. The authors would like to acknowledge the input of Dr Rachel Laws in the content analysis.

\section{Author details}

Centre for Primary Health Care and Equity, UNSW Australia, New South Wales, Australia. ${ }^{2}$ Centre for Obesity Management and Prevention Excellence in Primary Health Care, UNSW Australia, New South Wales, Australia. ${ }^{3}$ Faculty of Health, University of Technology Sydney, New South Wales, Australia.

Received: 4 November 2015 Accepted: 3 March 2016

Published online: 09 March 2016

\section{References}

1. Helena B, Miller GC, Henderson J, Bayram C, Valenti L, Harrison C, et al. General practice activity in Australia 2013-14. Sydney: Sydney University Press; 2014.

2. Australian Bureau of Statistics. Health literacy, Australia, cat.no. 4233.0. Canberra: ABS; 2008

3. National Health and Medical Research Council. Clinical practice guidelines for the management of overweight and obesity in adults, adolescents and children in Australia. Canberra: NHMRC; 2013.

4. National Health and Medical Research Council. Clinical practice guidelines for the management of overweight and obesity in adults, adolescents and children in Australia systematic review. NHMRC: Canberra; 2013.

5. Greaves CJ, Sheppard KE, Abraham C, Hardeman W, Roden M, Evans PH, et al. Systematic review of reviews of intervention components associated with increased effectiveness in dietary and physical activity interventions. BMC Public Health. 2011;11(1):119.

6. Belalcazar LM, Reboussin DM, Haffner SM, Hoogeveen RC, Kriska AM, Schwenke DC, et al. A 1-year lifestyle intervention for weight loss in individuals with type 2 diabetes reduces high c-reactive protein levels and identifies metabolic predictors of change from the Look AHEAD (Action for Health in Diabetes) study. Diabetes Care. 2010;33(11):2297-303.

7. Christian JG, Bessesen DH, Byers TE, Christian KK, Goldstein MG, Bock BC. Clinic-based support to help overweight patients with type 2 diabetes increase physical activity and lose weight. Arch Intern Med. 2008;168(2): 141-6.

8. Espeland M. Reduction in weight and cardiovascular disease risk factors in individuals with type 2 diabetes: one-year results of the Look AHEAD trial. Diabetes Care. 2007:30(6):1374-83.

9. Group LAR. Long term effects of a lifestyle intervention on weight and cardiovascular risk factors in individuals with type 2 diabetes: four year results of the Look AHEAD trial. Arch Intern Med. 2010;170(17):1566.

10. Schmitz KH, Hannan PJ, Stovitz SD, Bryan CJ, Warren M, Jensen MD. Strength training and adiposity in premenopausal women: strong, healthy, and empowered study. Am J Clin Nutr. 2007;86(3):566-72.

11. Silva MN, Vieira PN, Coutinho SR, Minderico CS, Matos MG, Sardinha LB, et al. Using self-determination theory to promote physical activity and weight control: a randomized controlled trial in women. J Behav Med. 2010:33(2): 110-22.

12. Teixeira PJ, Silva MN, Coutinho SR, Palmeira AL, Mata J, Vieira PN, et al, Mediators of weight loss and weight loss maintenance in middle-aged women. Obesity. 2010;18(4):725-35.

13. Harris M, Lloyd J. The role of Australian primary health care in the prevention of chronic disease. Australia: Australian Government Australian National Preventive Health Agency; 2012.
14. Berland GK, Elliott MN, Morales LS, Algazy Jl, Kravitz RL, Broder MS, et al. Health information on the internet: accessibility, quality, and readability in English and Spanish. JAMA. 2001;285(20):2612-21.

15. Vallance JK, Taylor LM, Lavallee C. Suitability and readability assessment of educational print resources related to physical activity: implications and recommendations for practice. Patient Educ Couns. 2008;72(2):342-9.

16. Ley P, Florio T. The use of readability formulas in health care. Psychol Health Med. 1996;1(1):7-28.

17. SA Health. Health literacy. In: Department for Health and Ageing, editor. South Australia: South Australia Health. Health literacy; 2013. http://www. sahealth.sa.gov.au/wps/wcm/connect/public+content/sa+health+internet/ clinical+resources/safety+and+quality/partnering+with+consumers+and+ +the+community/health+literacy. Accessed 14 May 2015.

18. Australian Curriculum, Assessment and Reporting Authority. National report on schooling in Australia. In: Australian Curriculum, Assessment and Reporting Authority. 2009. http://www.acara.edu.au/reporting/national_ report_on_schooling_2009/schools_and_schooling/school_structures.html. Accessed 15 May 2015

19. D'Alessandro DM, Kingsley P, Johnson-West J. The readability of pediatric patient education materials on the World Wide Web. Arch Pediatr Adolesc Med. 2001;155(7):807-12.

20. Badarudeen S, Sabharwal S. Readability of patient education materials from the American Academy of Orthopaedic Surgeons and Pediatric Orthopaedic Society of North America web sites. J Bone Joint Surg Am. 2008;90(1):199204.

21. Adkins $A D$, Singh $N N$. Reading level and readability of patient education materials in mental health. J Child Fam Stud. 2001;10(1):1-8.

22. Kirksey $\mathrm{O}$, Harper $\mathrm{K}$, Thompson S, Pringle M. Assessment of selected patient educational materials of various chain pharmacies. J Health Commun. 2004; 9(2):91-3.

23. White $P$, Smith $H$, Webley F, Frew A. A survey of the quality of information leaflets on hayfever available from general practices and community pharmacies. Clin Exp Allergy. 2004;34(9):1438-43.

24. Chesson Jr AL, Murphy PW, Arnold CL, Davis TC. Presentation and reading level of sleep brochures: are they appropriate for sleep disorders patients? Sleep. 1998:21(4):406-12.

25. Hoffmann T, McKenna K. Analysis of stroke patients' and carers' reading ability and the content and design of written materials: recommendations for improving written stroke information. Patient Educ Couns. 2006;60(3): 286-93.

26. Eames S, McKenna K, Worrall L, Read S. The suitability of written education materials for stroke survivors and their carers. Top Stroke Rehabil. 2003;10(3):70-83.

27. Wilson FL, Racine E, Tekieli V, Williams B. Literacy, readability and cultural barriers: critical factors to consider when educating older African Americans about anticoagulation therapy. J Clin Nurs. 2003;12(2):275-82.

28. Glanz K, Rudd J. Readability and content analysis of print cholesterol education materials. Patient Educ Couns. 1990;16(2):109-18.

29. Wilson FL, Williams BN. Assessing the readability of skin care and pressure ulcer patient education materials. J Wound Ostomy Continence Nurs. 2003; 30(4):224-30.

30. Faruqi N, Stocks N, Spooner C, El Haddad N, Harris MF. Research protocol: management of obesity in patients with low health literacy in primary health care. BMC Obesity. 2015:2(1):5

31. Flesch R. A new readability yardstick. J Appl Psychol. 1948;32(3):221.

32. Kincaid JP, Fishburne Jr RP, Rogers RL, Chissom BS. Derivation of new readability formulas (automated readability index, fog count and flesch reading ease formula) for navy enlisted personnel: DTIC Document. 1975.

33. Fry E. A readability formula that saves time. J Read. 1968;11(7):513-78.

34. McLaughlin GH. SMOG grading: a new readability formula. J Read. 1969; 12(8):639-46.

35. Doak CC, Doak LG, Root JH. Teaching patients with low literacy skills. Am J Nurs. 1996:96(12):16.

36. Edit Central. Edit Central. http://www.editcentral.com/gwt1/EditCentral.html. (2012). Accessed 10 April 2015.

37. National Health and Medical Research Council. Australian dietary guidelines. Canberra: National Health and Medical Research Council; 2013.

38. Purcell K, Sumithran P, Prendergast LA, Bouniu CJ, Delbridge E, Proietto J. The effect of rate of weight loss on long-term weight management: a randomised controlled trial. Lancet Diab Endocrinol. 2014;2(12):954-62.

39. Delbridge E, Proietto J. State of the science: VLED (Very Low Energy Diet) for obesity. Asia Pac J Clin Nutr. 2006;15(Suppl):49-54. 
40. Kao YH, Chang HH, Lee MJ, Chen CL. Tea, obesity, and diabetes. Mol Nutr Food Res. 2006;50(2):188-210.

41. Wolfram S, Wang Y, Thielecke F. Anti-obesity effects of green tea: from bedside to bench. Mol Nutr Food Res. 2006;50(2):176-87.

42. Phung OJ, Baker WL, Matthews LJ, Lanosa M, Thorne A, Coleman Cl. Effect of green tea catechins with or without caffeine on anthropometric measures: a systematic review and meta-analysis. Am J Clin Nutr. 2010;91 (1):73-81.

43. Nawrot P, Jordan S, Eastwood J, Rotstein J, Hugenholtz A, Feeley M. Effects of caffeine on human health. Food Addit Contam. 2003;20(1):1-30.

44. Snitker S, Fujishima Y, Shen H, Ott S, Pi-Sunyer X, Furuhata Y, et al. Effects of novel capsinoid treatment on fatness and energy metabolism in humans: possible pharmacogenetic implications. Am J Clin Nutr. 2009;89(1):45-50.

45. Galgani JE, Ravussin E. Effect of dihydrocapsiate on resting metabolic rate in humans. Am J Clin Nutr. 2010;92(5):1089-93.

46. Galgani JE, Ryan DH, Ravussin E. Effect of capsinoids on energy metabolism in human subjects. Br J Nutr. 2010;103(1):38-42.

47. Inoue N, Matsunaga $Y$, Satoh $H$, Takahashi M. Enhanced energy expenditure and fat oxidation in humans with high BMI scores by the ingestion of novel and non-pungent capsaicin analogues (capsinoids). Biosci Biotechnol Biochem. 2007;71(2):380-9.

48. Kools M, Ruiter RA, van de Wiel MW, Kok G. Increasing readers' comprehension of health education brochures: a qualitative study into how professional writers make texts coherent. Health Educ Behav. 2004;31(6):720-40.

49. Whittingham JR, Ruiter RA, Castermans D, Huiberts A, Kok G. Designing effective health education materials: experimental pre-testing of a theorybased brochure to increase knowledge. Health Educ Res. 2008;23(3):414-26.

50. Royal Australian College of General Practitioners. Standards for general practices (4th edition). Melbourne: RACGP. 2010. http://www.racgp.org.au/ download/documents/Standards/standards4thedition.pdf. Accessed 16 May 2015

\section{Submit your next manuscript to BioMed Central and we will help you at every step:}

- We accept pre-submission inquiries

- Our selector tool helps you to find the most relevant journal

- We provide round the clock customer support

- Convenient online submission

- Thorough peer review

- Inclusion in PubMed and all major indexing services

- Maximum visibility for your research

Submit your manuscript at www.biomedcentral.com/submit

C Biomed Central 